Open Access

\title{
Potential applications of unmanned ground and aerial vehicles to mitigate challenges of transport and logistics-related critical success factors in the humanitarian supply chain
}

\author{
Muhammad Azmat ${ }^{*}$ (D) and Sebastian Kummer
}

\author{
*Correspondence: mazmat@wu.ac. \\ at; m.azmat@live.com \\ Institute for Transport and Logistics \\ Management, WU (Vienna \\ University of Economics and \\ Business), Welthandelsplatz 1, 1020 \\ Vienna, Austria
}

\begin{abstract}
The present decade has seen an upsurge in the research on the applications of autonomous vehicles and drones to present innovative and sustainable solutions for traditional transportation and logistical challenges. Similarly, in this study, we propose using autonomous cars and drones to resolve conventional logistics and transport challenges faced by international humanitarian organizations (IHOs) during a relief operation. We do so by identifying, shortlisting, and elaborating critical success factors or key transport and logistics challenges from the existing humanitarian literature and present a conceptual model to mitigate these challenges by integrating unmanned ground (UGVs) and aerial vehicles (UAVs) in the humanitarian supply chain. To understand how this novel idea of using UGVs and UAVs could help IHOs, we drafted three research questions, first focusing on the identification of existing challenges, second concentrating on remediation of these challenges, and the third to understand realization timeline for UGVs and UAVs. This lead to the development of a semi-structured, open-ended questionnaire to record the respondents' perspectives on the existing challenges and their potential solutions. We gathered data form, ten interviewees, with substantial experience in the humanitarian sector from six IHOs stationed in Pakistan and Austria. In light of the feedback for the second research question, we present a conceptual model of integrating UAVs and UGVs in the relief chain. The results of the study indicate that technological advancement in mobility withholds the potential to mitigate the existing challenges faced by $\mathrm{HO}$. However, IHOs tend to be reluctant in adapting UGVs compared to UAVs. The results also indicate that the adaptation of these technologies is subject to their technical maturity, and there are no significant differences in opinions found between the $\mathrm{HHO}$ s from Pakistan and Austria.

Keywords: UGVs, UAVs, Autonomous vehicles, Autonomous drones, Humanitarian supply chain, Humanitarian logistics, Disaster management, Disaster relief operation, CSF, Critical success factors
\end{abstract}




\section{Introduction}

The last few decades have seen an unprecedented amplification in the number and complexity of disasters worldwide (Tatham and Houghton 2011; Richey et al. 2009). Such an increase in the frequency of catastrophe has put enormous pressure on the weakest links in the humanitarian supply chain. These links, which may also be referred to as threshold potential of the humanitarian operation, can be severely affected in such situations hampering the effectiveness and efficiency of the humanitarian supply chain, which ultimately results in affecting the beneficiaries. These links and threshold potentials are discussed in the humanitarian literature as challenges, limitations, limiting factors, or critical success factors (CSF) (Yadav and Barve 2015; Oloruntoba 2010; Pettit and Beresford 2009). These factors or challenges may include but are not limited to extreme urgency, disaster-related uncertainties, lack of resources, infrastructure, human resources, limited availability of vehicles, etc. (Day et al. 2012; Martinez et al. 2011). However, over time, smart and technologically advanced solutions are being evolved to counter these challenges and assist humanitarian operations (Young 2006).

When a natural disaster occurs in a populated zone, an agile and effective organization of the disaster management is required to assist the affected population, to minimize the number of victims and to limit the economic impact (Tanzi et al. 2016). According to Moshtari and Gonçalves (2016) and Balcik et al. (2010), the first hand reliable, adequate, and timely information about the disaster's location, its intensity, the damage it caused to infrastructure and the number of the affected population is significant for the success of relief operation. However, in many cases, such information is not easy to access. Therefore, Bravo and Leiras (2015) noted that one of several potential applications of unmanned aerial vehicles (UAVs) could be gathering such information accurately and swiftly and be able to assist the humanitarian organizations in relief operations. Keeping in view the critical role UAVs can play in saving lives, lately, a hand full of academic researchers, startups and non-profit organizations have started exploring the opportunities of using such vehicles in disaster relief operations.

Similarly, the development of unmanned ground vehicles (UGVs), systems, and technologies can potentially lead to significant advances in life-saving activities. In parallel with design innovation, new system analysis techniques must be used to assess the relative merits of disaster relief and emergency response system concepts (Young 2006). However, not many researchers have shown a keen interest in exploring the opportunities associated with using UGVs in humanitarian settings. Hence, the prime focus of the academic community is to explore the opportunities related to using autonomous or remotely controlled drones in disaster scenarios, for instance, Tatham et al. (2017a) and Tatham et al. (2017b) suggest using remotely piloted aircraft for high-quality imagery of disaster-struck areas and providing medical supplies in relief operation, Whereas, Dobrovnik et al. (2018) talk about using how Blockchain can revolutionize logistical operations.

Therefore, the objective of this particular research is first to identify and shortlist transport and logistics-related CSFs and later examine how not only UAVs but also UGVs can be used in mitigating these transport and logistics-related challenges in humanitarian settings. Furthermore, we also explore if these two innovative mobility options can work in conjunction with each other to mitigate the transport and logistics 
challenges faced by humanitarian organizations. Besides, to know the expected adaptation timeline for these technologies by the IHOs.

\section{Research questions}

To address the objective of this study, the following research questions (Table 1) are drafted; each of these questions serves the purpose of exploring a different scope.

\section{Organization of the paper}

This paper is divided into five Sections, each contributing to accomplishing the objective of this study. In Section 1, we briefly highlight what the research gaps are and how we propose to bridge the gaps. Section 2 discusses the state of the art, where we present a comprehensive understanding of the humanitarian relief operations and discuss shortlisted CSF. Followed by the discussion on potential applications and challenges of using UGVs and UAVs in relief operations, we also present a succinct case of using UAVs in Papa New Guinea (PNG) to help the reader understand how the relief operation works in a real-life scenario. Subsequently, Section 3 discusses the methodological approach for this study and elaborate on how data was collected and assessed to find answers to the research questions. In Section 4, we summarize the results, answer the research questions, and present the conceptual model to integrate UGVs and UAVs. Section 5 presents the conclusion and key take away from this study and also present its limitations and future research prospect.

\section{Literature review}

This section briefly highlights the functioning of a humanitarian supply chain, followed by some of the most important transport and logistics related to CSF. Moreover, it briefly elaborates on the potential applications of UGVs and UAVs in relief operations and briefly discusses the challenges in the realization of these applications. Last but not least, we address the research questions designed for this study in the light of literature.

\section{Humanitarian relief operation and critical success factors}

According to Jahre et al. (2007), noted that the focus of the humanitarian relief operation (HRO) is to, "design the transportation of first aid material, food, equipment, and rescue personnel from supply points to a large number of destination nodes geographically scattered over the disaster region and the evacuation and transfer of people affected by the disaster to the health care centers safely and very rapidly. Moreover, Van Wassenhove (2017) suggests, "A successful humanitarian operation mitigates the urgent needs of a population with a sustainable reduction of their vulnerability in the shortest amount of time and with the least amount of resources."

Table 1 Research questions

\begin{tabular}{lll}
\hline No. & Scope & Research Question \\
\hline 1 & Identification & $\begin{array}{l}\text { What are the main transport and logistics challenges faced by humanitarian organizations } \\
\text { during a relief operation? }\end{array}$ \\
2 & Remediation & $\begin{array}{l}\text { How to alleviate transport and logistics-related critical issues in the disaster relief operation, } \\
\text { using UGVs and UAVs? }\end{array}$ \\
3 & Realization & $\begin{array}{l}\text { How long could it take UGV and UAV technology to mature, and will IHOs integrate them } \\
\text { in their disaster relief operation? }\end{array}$
\end{tabular}


A relief operation involves several actors like donors, host government, local and international non-governmental organizations, military, and suppliers, etc. (Maghsoudi et al. 2018; Costa et al. 2012; Jahre et al. 2007) and According to Maghsoudi et al. (2018), a typical humanitarian relief operation mostly consists of disaster relief supply chain. It includes activities like needs assessment, planning, procurement, warehousing, and distribution of the supplies to beneficiaries. However, relief organizations play one of the essential roles in the relief operation; they serve as the point of contact for all players involved in the HRO, and most importantly beneficiaries look towards them for all the possible help they can get (Ferris 2005; Van Wassenhove 2017).

Therefore, to respond to a disaster efficiently and effectively, all participating relief organizations need to enhance their capabilities. Yadav and Barve (2015) suggest that this can be achieved by carefully managing certain activities and by dividing management processes into factors. In humanitarian literature, these factors are referred to as CSF (Eriksson and Karlsson 2017; Kabra and Ramesh 2015b; Yadav and Barve 2015; Pettit and Beresford 2009) or Key success factors (Oloruntoba 2010).

The concept of CSF has been thoroughly applied in different circumstances in supply chain management, operational management, organizational management, and enterprise resource management (Celik et al. 2014). According to (Oloruntoba 2010) "CSFs are the conditions, characteristics, or variables that when properly cultivated, sustained, maintained or managed can have a significant impact on the success of a company or its endeavor." However, in contrast with commercial settings, CSF in humanitarian settings is not studied to increase the profits but to provide effective and efficient humanitarian services and save time. Therefore, it is crucial to define CSFs to avoid or minimize the risk of failure in humanitarian operations (Eriksson and Karlsson 2017; Pettit and Beresford 2009).

It may be noted that CSFs like donor restrictions, host government policies, limited resources, lack of transport infrastructure, blocked supply lines, custom and clearance issues, limited transport vehicles, workforce shortages, information collection, organization's structure, and culture, and coordination and collaboration are some of the most discussed CSFs in the humanitarian literature. These CSFs are mainly highlighted in last decade by the authors like (Azmat et al. 2019a; Dasaklis and Pappis 2018; Yadav and Barve 2018; Bealt et al. 2016; Dale and Dulaimi 2016; Ngwenya and Naude 2016; Kabra and Ramesh 2015a; Costa et al. 2012; Martinez et al. 2011; Balcik et al. 2010). However, for this study we will focus mainly on the transport and logistics-related CSFs under discussion in humanitarian literature (Table 2).

Table 2 List of most discussed transport and logistics-related CSF for relief operation

\begin{tabular}{|c|c|c|}
\hline No. & Factor & References \\
\hline 1 & Lack of transport infrastructure & $\begin{array}{l}\text { (Yadav and Barve 2015, Martinez et al. 2011, Jahre et al. 2007, Costa } \\
\text { et al. 2012, Richey et al. 2009, Balcik et al. 2010, Balcik and Beamon } \\
\text { 2008, Ngwenya and Naude 2016) }\end{array}$ \\
\hline 2 & Rugged topography & (Jahre et al. 2007, Balcik et al. 2010) \\
\hline 3 & Custom clearance & (Dube et al. 2016, Ngwenya and Naude 2016, Scholten et al. 2006) \\
\hline 4 & Limited transport capacities & (Balcik et al. 2010, Balcik and Beamon 2008, Ngwenya and Naude 2016) \\
\hline 5 & $\begin{array}{l}\text { Limited transportation resources } \\
\text { (Vehicles \& Drivers) }\end{array}$ & $\begin{array}{l}\text { (Balcik et al. 2010, Balcik and Beamon 2008, Ngwenya and Naude 2016, } \\
\text { Martinez et al. 2011) }\end{array}$ \\
\hline
\end{tabular}




\section{Transport and logistics-related CSFs}

According to Jahre et al. (2007) and Van Wassenhove (2017), logistical activities may constitute up to $80 \%$ of the humanitarian relief operation and are involved in every stage of relief process, thus, making it the most critical factors in providing humanitarian aid. Furthermore, Martinez et al. (2011) highlight that transport activities (inland) mainly include but are not limited to transporting staff, relief items, and material to the affected area. Timely transportation of people and relief supplies is essential for the success of relief operations, as they play a primary role in providing relief and assistance to the beneficiaries.

Moreover, Balcik et al. (2010) and Ngwenya and Naude (2016) suggest that transportation is considered one of the most significant and challenging part of the disaster relief operation. After a disaster strikes, it leaves infrastructure damaged or thoroughly washed-out; most of the supply lines blocked, transportation resources become scares and above all, transporting a bulk load of supplies to beneficiaries in the affected area makes this already difficult task even more challenging. These topographical challenges constrain the use of already scarce resources. They further added that complex topographical characteristics of affected areas, like mountainous terrain or extremely harsh weather, could easily affect the relief operation. Which results in a delay to provide not only the aid and supplies (for example, remote areas may only be reachable by small trucks or helicopters, whereas larger vehicles may only be used for nearby areas) but also to assess the magnitude of catastrophe (Balcik et al. 2010).

Jahre et al. (2007) further suggest that disaster relief operation struggles with various state of affairs ranging from no-electricity to limited or lack transport infrastructure, and Martinez et al. (2011) also concur with that. Moreover, the unpredictability of demand for goods in disasters makes humanitarian logistics more complex and sets it apart from its commercial counterpart. Therefore, Costa et al. (2012) suggest, there are two main types of information needed to carry out logistical activities effectively and efficiently in humanitarian settings: (i) needs information (needs assessment, size of the affected population and additional adversity vulnerability, damage levels, pre-existing poverty), and (ii) logistics information (distance from the hub, transportation capacity on a given day, access roads open on a given day, existing cargo handling orders).

Costa et al. (2012) further explained that the case of the 2005 earthquake in Pakistan is a good example understand how topographical challenges hinder the relief process. In the 2005 earthquake, most of the affected area was on higher altitude, where the infrastructure was wiped out after the disaster. Besides, limited transport capacities also prevented the quick and efficient dispatch of relief goods to the most deprived areas. Therefore, in this case, transport and logistics part of relief operation was one of the most critical factors for a successful relief operation and providing relief to the victims, this also confirms the importance of exploring the solutions for the transport and logistics-related CSF. Apart from the rugged topography, vehicle shortages, limited transport capacities, and lack of infrastructure were also a few critical challenges faced by IHOs.

Furthermore, Dube et al. (2016) noted that apart from identification of needs (Costa et al. 2012) other external factors such as unpredictable clearance times at ports, complex, incomplete information, and restrictions imposed by the host government on incoming shipments combined with limited human resource adds to the challenges of 
relief operation. They further suggest that such issues mainly arise with the first aid medications or certain food items like genetically modified food items. Whereas (Martinez et al. 2011) added that operating conditions, demand uncertainty, and donors restrictions are also a few external factors that may hinder the relief process.

\section{Potential applications of UGVs in HRO}

In the present decade, the potential applications of UGVs commonly referred to as autonomous vehicles or self-driving cars/trucks are under discussion in commercial settings, and several researchers have highlighted that these vehicles have the potential of significantly reducing the transport and logistics-related challenges in complex urban environments. For instance, the benefits of using UGVs in urban or commercial settings include but are not limited to, increased safety, reduced congestion, better fuel consumption, reduced emissions, reduced costs of ownership, elimination of drive time restrictions and transporting disabled or older people (Azmat et al. 2019b; Gkartzonikas and Gkritza 2019; Wintersberger et al. 2019; Azmat et al. 2018; Milakis et al. 2017; Mahmassani 2016; Litman 2015; Kyriakidis et al. 2015; Bierstedt et al. 2014).

Even though researchers have highlighted the potential use case scenarios of UGVs in a complex environment, not many researchers have talked about exploring the potential of these advanced vehicles in humanitarian settings. However, after an extensive literature search, we managed to find a hand full of researchers like Mosterman et al. (2014), Ivancevic and Yue (2016), Desaulniers et al. (2013) and Seitz (2015) who have tried to highlight the potential of using UGVs alongside UAVs in humanitarian operations.

According to Mosterman et al. (2014), disaster response and recovery are two such phases where a fleet of UGVs can be of substantial importance. They suggest, once these vehicles are able to understand the idiosyncratic nature of emergencies, which can differ substantially from the nature of similar activity in everyday life, it can revolutionize the response and recovery phase. These vehicles are supposed to be readily available, very responsive, agile, and interactive. According to them, the disaster is a time-critical scenario; therefore, fast response times are critical, and these response times combined with other innovative cyber-physical systems may lead to an ideal solution for emergency response. Furthermore, they suggest that the UGVs that can carry large payloads can help first responders, as they can be instantly deployed. They also suggest that these vehicles would be smart and could quickly compute not only the optimal deployment locations but also configure the optimal vehicle route that is faster and safer. Moreover, Ivancevic and Yue (2016) suggest that the efficiency and effectiveness of such relief operations can dramatically increase by using UGVs in conjunction with UAVs.

\section{Challenges in the realization of applications for UGVs}

Although the technological advancements like UGVs are inching towards revolutionizing the transport and logistics, as we know it today, it still faces many critical challenges in realization both in commercial and humanitarian settings. According to Mosterman et al. (2014), a critical issue is the non-existence of such platforms that are flexible and extendable to support continuous evolution yet sufficiently rich and rigorous to enable a broad range of features with potentially safety-critical implications. They further 
added that UGVs that operate near humans must be safe as well as behave intuitively in mixed-initiative collaboration.

Moreover, Desaulniers et al. (2013) lay the foundation on the technical grounds and suggests that to achieve advantages mentioned above in an unstructured outdoor environment, a UGV needs to be capable of estimating the travel ability of the terrain in order to navigate safely and fulfill the desired task. Thus the UGVs would necessarily require sophisticated technological skills combined with similar hardware to support the relief activities as accurately and in a timely fashion as possible. Nonetheless, a report by Seitz (2015), which constitutes of the interviews from the technology experts, suggests that UGVs and more advanced humanoid robots to assist disaster response are slow in coming, and it might take several years until this technology is mature enough to be used in real-world disaster situations.

\section{Potential applications of UAVs in HRO}

The potential of UAVs is no hidden secret anymore. Hall and Coyne (2013) noted that World governments spent more than $\$ 6.6$ billion on UAV, commonly referred to as 'drones' (both remotely controlled and autonomous) in 2012. They mentioned that this number might increase to $\$ 11.4$ billion a year over the next decade. While the number of drones currently in operation is unknown, the International Institute for Strategic Studies has identified 56 different types of UAVs in use in eleven different countries. There have been numerous discussions over the usage of drones in a non-military perspective; Bravo and Leiras (2015) noted several potential non-military applications of drones discussed by different research communities. For instance, few of the main floating ideas include but are not limited to seismic risk assessment, surveillance, transportation, disaster response, aerial imagery for disaster assessment, disaster prevention, and mitigation, search and rescue operations, land resources monitoring, forest fire prevention and so forth.

According to Câmara (2014), Nowadays, UAVs have the capability of performing many complex missions with a strict time constraint. Due to improved human safety, UAVs are preferred not only in the military but also in a civil application such as urban search and rescue operations. The researcher further mentioned, in a calamity scenario, the first couple of hours are very crucial. The chances of rescuing people alive are the highest in the first few hours. However, it is also the time when the available human resources are scarce. Ivancevic and Yue (2016) also agree with Câmara (2014), that in many disaster scenarios such as earthquakes, avalanches, mudslides, and explosions, it is common for people to be injured and covered by debris. These people require fast attention, and all the available human resources need to concentrate on the search and rescue task.

Nevertheless, the rescue efforts need to be coordinated, and the disaster's impact needs to be characterized as fast as possible. The time pressure, scarcity of human resources and the urgent need for information are more than enough reasons that justify the use of autonomous drones to collect the maximum of information and provide first aid in the affected areas. De Sousa et al. (2008) suggest that autonomous vehicles, in general, are capable of 'dirty, dull, and dangerous (3D) missions,' and they have been proving their competence in a military operation. However, in humanitarian settings, the specific role of these vehicles is not yet clear. They suggest UAVs might be helpful in surveillance and assessment-related activities and in limited cases, might serve as first responders. 


\section{Case of using UAVs in Papua New Guinea to cure tuberculosis}

Tuberculosis (TB) prevalence in PNG is among the highest in the world, 541 cases/100, 000 population/year, with some pockets reported being three times higher, prompting Médecins Sans Frontières (MSF) to respond and reach the most affected communities (MSF 2014). Soon MSF realized that geographical conditions pose a formidable barrier; the limited access to healthcare diagnostics due to severe logistical constraints in PNG has led MSF to be one of the first humanitarian organizations to test the use of UAVs (FSD 2016). Referring to the information on the Commonwealth's website (CWO 2017) and Central Intelligence Agency's website (CIA 2017), PNG comprises about 600 small islands and has some $5150 \mathrm{~km}$ of coastline. The road and transport infrastructure are deplorable, or in many places nonexistent, the rugged mountainous environment hampers the construction of roads, and the entire national road network extends to 19 , $600 \mathrm{~km}$ (3.5\% paved).

Besides, poor data collection and reporting procedures, along with inadequate infection control activities, result in low case detection rates of TB. After analyzing the situation, MSF set up a new laboratory in the general hospital, which could cut the TB test result delays down from weeks to just $2 \mathrm{~h}$. However, the more significant challenge was to reach out to the higher number of potential patients in rural and remote areas that are geographically inaccessible due to the poor condition of the roads. Thus, to resolve this issue MSF and US Company Matternet trialed the use of small quadcopter (UAVs) to transport sputum samples of patients with suspected TB from remote health centers to Kerema general hospital for testing and transporting results and treatments back to the patients (Figs. 1 and 2).

Currently, the UAVs are capable of traveling at up to $60 \mathrm{~km} / \mathrm{h}$ with a maximum range of $28 \mathrm{~km}$ in favorable conditions and can only carry a light payload. However, it is predicted that their range will increase rapidly in the coming years as new lighter and longer-lasting batteries are being developed. The UAVs may also be launched by a smartphone, with the goal that non-technical staff can operate them without assistance. While there is still fine-tuning of the UAV system that needs to be done during the

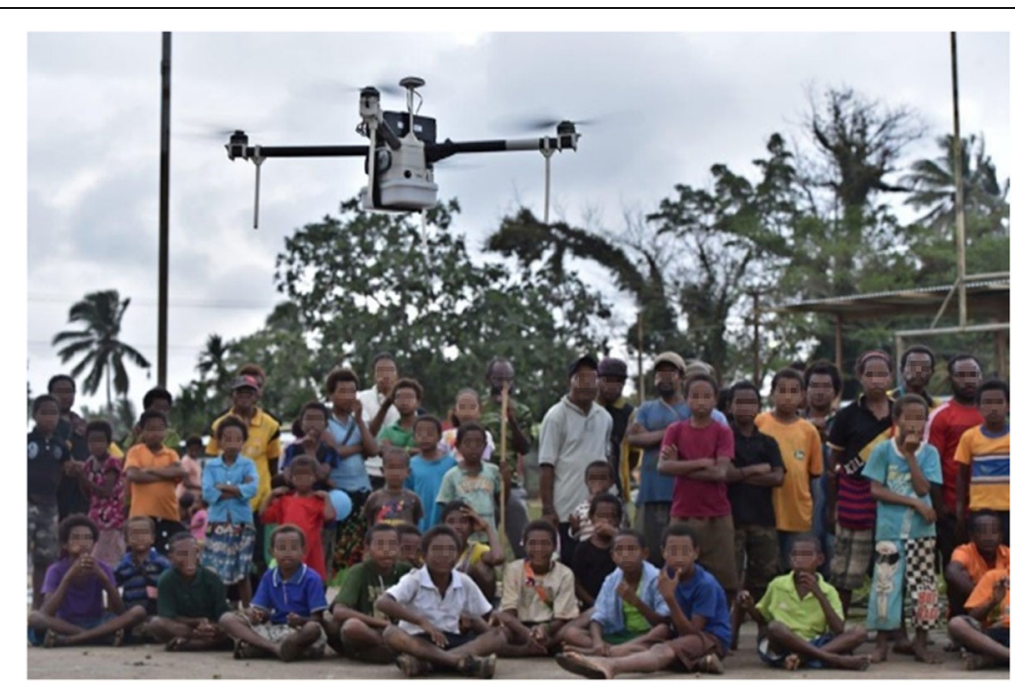

Fig. 1 UAV demonstration flight - MSF (2014) 


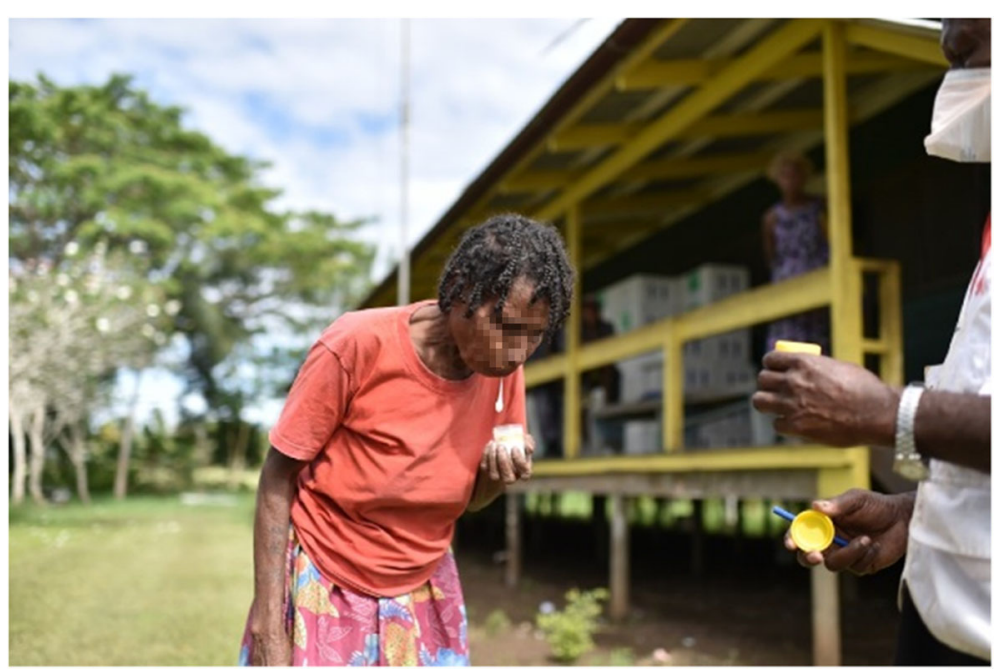

Fig. 2 Patient with suspected TB - MSF (2014)

trial phase, initial signs indicate that this may be a useful method of connecting remote health centers to otherwise inaccessible hospitals in the future. MSF considered this pilot project to be just a trial of the technology and did not carry out a comparative analysis of costs to determine whether payload delivery by drone would be less costly than by car. The main benefits were reduced delivery time and being able to avoid the risk of driving a vehicle through very difficult topographies (FSD 2016).

\section{Challenges in the realization of applications for UAVs}

According to De Sousa et al. (2008), to unleash the full potential of UAVs they have to overcome several challenges like 1) lack of legal frameworks for the operation of these vehicles, 2) lack of standards for interoperability; 3) lack of concepts of operation that include a role for autonomous vehicles; 4) lack of guidelines for best practice; 5) relative infancy of the technologies and of the commercially available solutions; 6) lack of trained operators; and 7) high cost of commercially available solutions. They further added that these challenges are blessing in disguise as they teach valuable lessons and help to build an ultimate system to accommodate such vehicles into the system.

\section{Methodology}

This is exploratory qualitative research, designed to uncover trends in thought and opinions, and identify the problem currently being faced by different Humanitarian organizations during disaster relief (Wyse 2011). Moreover, Mahmood et al. (2019) Also suggest that qualitative methods help to capture not only the stakeholders' perception but also elaborate on the context in which they are held. Therefore, to answer the research questions drafted for this study, we used the data triangulation approach. Patton (2002) noted that triangulation is a method used by qualitative researchers to check and establish validity in their studies by analyzing a research question from multiple perspectives. Similarly, Thurmond (2001) suggest that data triangulation may result in increased confidence in research data, creating innovative ways of understanding a phenomenon, and providing a clearer understanding of the problem. 
In this study, we collected data from three different sources to establish a proper ground to answer the research questions. Firstly, critical success factors were collected from the existing humanitarian literature. Secondly, we referred to the grey literature, for instance, IHOs websites, yearly reports, and field reports. Thirdly, primary data, which was collected using semi-structured interviews.

\section{Primary data}

The primary data for the research was collected by interviewing international humanitarian organizations (IHOs) via Semi-structured, open-ended interviews referring to the methodology used by (Scarpin and Silva 2014; Stajura et al. 2012). According to Martinez et al. (2011), IHOs are organizations that tend to provide relief on humanitarian grounds. A typical IHO is usually multinational with its headquarters in some developed country while most of its operations are in developing or disaster-prone countries. Therefore, for this research, we selected six such IHOs that has been actively involved in the relief operation, and we selected them based on convenience sampling technique. We selected three organizations from the developed and less disaster-prone country, Austria, and three from developing and highly disaster-prone country, Pakistan. Which gives our research a breadth needed to cover the broader perspective and helps us in understanding how different relief organizations think in the central European country compared with south Asian country. To keep the identity anonymous, the names of the respondents and their organizations would not be disclosed. Table 3 below gives a holistic overview of the respondents' profiles who were interviewed.

The interview questions were divided into three blocks; the first block of questions focused on general information of the organization, including its global footprint, number of employees, type of activities, funds, and so forth. The second block of questions was directed at asking transport and logistics-related challenges these organizations face during a relief operation, including its response time and transport-related costs, etc. Whereas, the third block of questions was related to the mitigation of these challenges using UAVs and UGVs, including their potential applications, challenges, and discussion about their adaptation timeline. Based on the feedback and discussion on how UAVs and UGVs may be integrated into the humanitarian supply chain, a hypothetical mobility model was developed, which uses these two technologies to alleviate

\begin{tabular}{|c|c|c|c|c|c|c|c|}
\hline $\begin{array}{l}\text { Org. } \\
\text { Type }\end{array}$ & $\begin{array}{l}\text { Relief operations } \\
\text { in (countries) }\end{array}$ & $\begin{array}{l}\text { Number of } \\
\text { interviewees }\end{array}$ & $\begin{array}{l}\text { Interview } \\
\text { mode }\end{array}$ & $\begin{array}{l}\text { Interview } \\
\text { time }\end{array}$ & $\begin{array}{l}\text { Position held / } \\
\text { Department }\end{array}$ & $\begin{array}{l}\text { Experience } \\
\text { in years }\end{array}$ & Country \\
\hline $\begin{array}{l}\text { IHO } \\
\mathrm{A}\end{array}$ & 70 & 1 & In-person & $1 \mathrm{~h} 39 \mathrm{~min}$ & $\begin{array}{l}\text { International coordinator } \\
\text { and Logistics head }\end{array}$ & 13 & Austria \\
\hline $\begin{array}{l}\mathrm{IHO} \\
\mathrm{B}\end{array}$ & 190 & 2 & In-person & $1 \mathrm{~h} 50 \mathrm{~min}$ & SCM and logistics & $15 / 12$ & Austria \\
\hline $\begin{array}{l}\mathrm{IHO} \\
\mathrm{C}\end{array}$ & 160 & 2 & In-person & $1 \mathrm{~h} 20 \mathrm{~min}$ & $\begin{array}{l}\text { International Operations } \\
\text { / SCM }\end{array}$ & $7 / 5$ & Austria \\
\hline $\begin{array}{l}\text { IHO } \\
\mathrm{D}\end{array}$ & 08 & 1 & Skype & $1 \mathrm{~h} 12 \mathrm{~min}$ & Logistics manager & 8 & Pakistan \\
\hline $\begin{array}{l}\text { IHO } \\
\mathrm{E}\end{array}$ & 18 & 2 & Skype & $1 \mathrm{~h} 16 \min$ & $\begin{array}{l}\text { Head of SCM / Field } \\
\text { Officer }\end{array}$ & $17 / 9$ & Pakistan \\
\hline $\begin{array}{l}\text { IHO } \\
\mathrm{F}\end{array}$ & 26 & 2 & Skype & $1 \mathrm{~h} 26 \mathrm{~min}$ & $\begin{array}{l}\text { Logistics and } \\
\text { coordination manager }\end{array}$ & $9 / 10$ & Pakistan \\
\hline
\end{tabular}


CSF related to transport and logistics. During the semi-structured interview sessions, interviewees were allowed to deviate from the question and add any specific example experience and any other information which could support their arguments.

\section{Secondary data}

The secondary data for the research was collected referring to the methodology used by several researchers like Azmat et al. (2019b), Azmat et al. (2018), Burkart et al. (2016), Seuring and Gold (2012), Jahre et al. (2007), we gathered relevant literature using topical key-word search query along with exploring the references of the key articles in order to develop the understanding of the current state of the field. Moreover, the grey literature, including organizational reports, websites, and newspaper articles, were also referred to where needed.

\section{Analysis and discussion}

IHOs' demographics

The information gathered through the first block of questions demonstrates that all participating organizations have excellent international exposure and have thousands of employees working in different countries. Furthermore, all IHOs are actively involved in disaster relief activities. However, each IHO performs a multitude of activities like providing aid in endemic and epidemic disease, social violence, healthcare, children and women protection, HIV/AIDS, community service, polio eradication, and providing ambulance services ... etcetera. During the interview analysis, we also discovered that between $30 \%$ and $40 \%$ of funds are earmarked, which limits the functionality and freedom of these IHOs. More interestingly, the collected data showed that for three IHOs most significant share of funds comes from the private sector, whereas for the remaining three, it comes from the public sector (Table 4).

\section{Transport and logistics challenges for IHOs}

The second block of questions encouraged the respondents to talk about the transport and logistics-related challenges they face during a disaster relief operation (the summary of their responses can be seen in Table 5). To understand the agility and flexibility of their current supply chain model, they were inquired about the time they need to respond to an emergency both locally and internationally. The literature on the humanitarian supply chain suggests that the first $72 \mathrm{~h}$ are the most critical hours for the response phase, and it could be the difference between life and death (Maghsoudi et al. 2018; Azmat and Kummer 2019; Tatham and Houghton 2011). We found out that all participating IHOs are capable of responding to any natural or manmade disaster internationally within 24 to 96 $\mathrm{h}$, depending on the distance to disaster location, the severity of the disaster and the agility of custom and immigration process., and on the national level within 1 and $24 \mathrm{~h}$.

Nonetheless, it concludes that most of the organizations can manage to respond to an emergency in a time-critical manner. However, all organizations stressed on optimizing the processes which usually causes a delay in response time, which leads to the identification of challenges related to transport and logistics, which affect the response time.

The respondents highlighted that transport and logistics-related challenges could affect the response time in numerous ways. Most importantly, long distances, custom clearance, or border control, host government policies for IHOs are among the top 


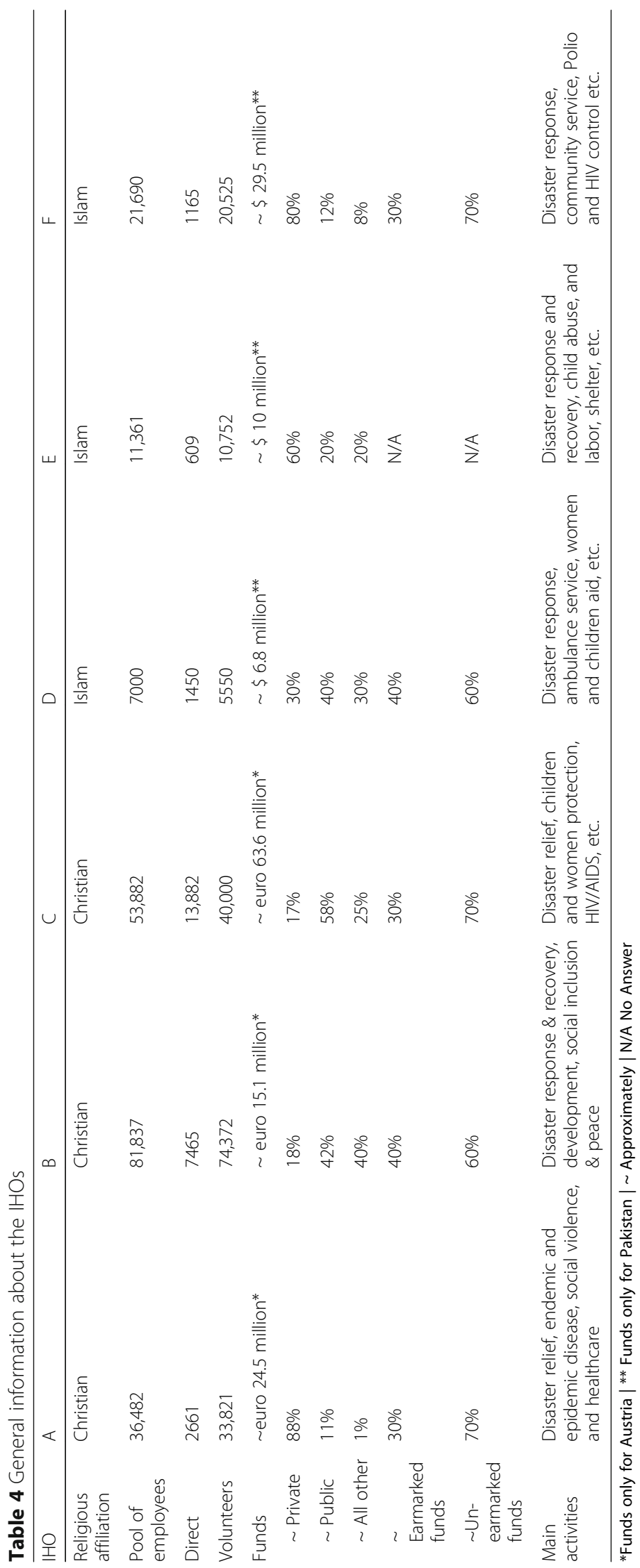




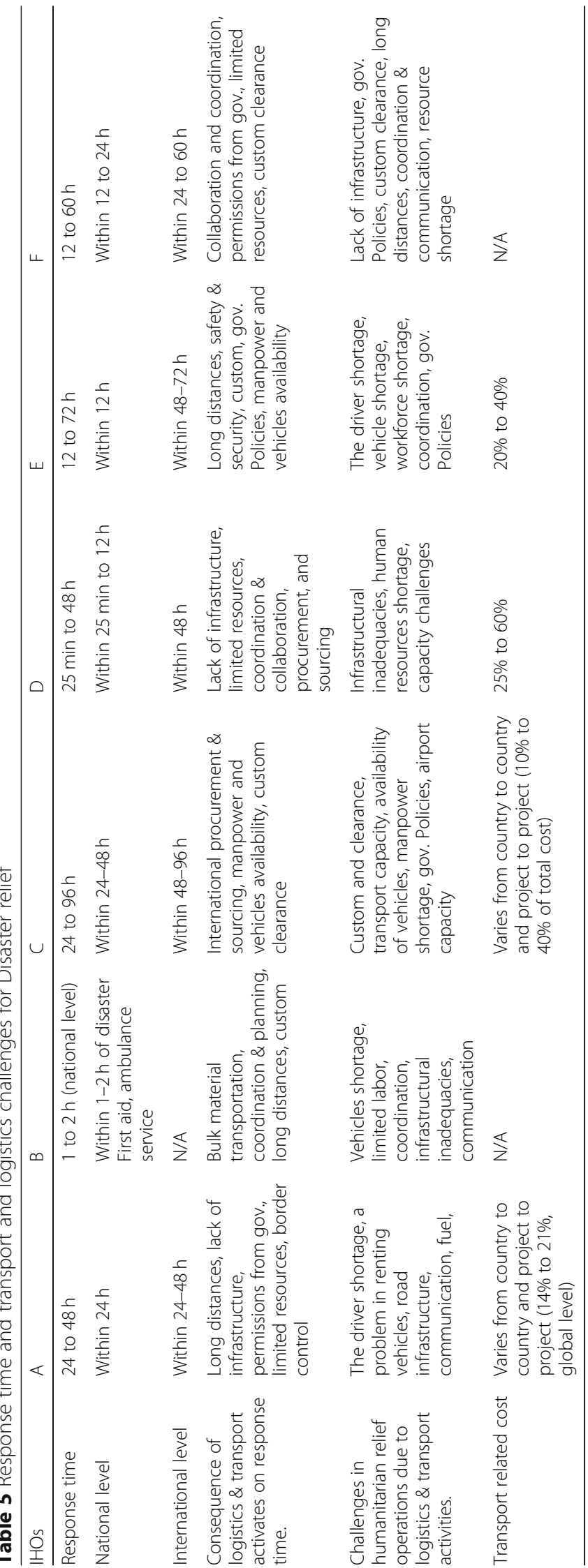


reasons for delays in response time internationally. However, respondents also mentioned that other critical factors which limit the effectiveness and efficiency of the disaster response may include but are not limited to, Lack of transport and logistics infrastructure, government interferences, finding the right carrier for bulk material transportation and finding the right person to do the job right (limited knowledgeable workforce). In a nutshell, it has been observed through the analysis of responses that logistics and transport-related activities have a significant impact on the response time in disaster relief operations.

Additionally, respondents mentioned several hindrances sabotaging agility of logistics and transport activities, which make humanitarian operations very challenging. Some of the significant challenges include but are not limited to, scarcity in resource (human resources \& vehicle) in terms of ability and capacity takes first place on the list of challenges. Furthermore, the shortage of skilled workforce and shortage of vehicles and drivers during any insurgency is another most significant cause of delays in operational activities. Whereas, Infrastructural inadequacies (lack of road networks and other facilities) and coordination \& communication (which is a backbone for any operation to be timely and successful) within and among different organizations involved in relief operation is also one of the significant issues.

Lastly, to understand what percentage of the total operational costs are incurred during the logistics and transport activates, respondents were inquired about the cost of transport and logistics activities. The respondents found it to be one of the most challenging questions to answer. They all agreed that the costs vary greatly based on several factors, which include but are not limited to distance, location, and available resources, etc. However, they managed to give us the vague accumulated figures for local and international activities combined, which could be anywhere between $10 \%$ and $60 \%$ for all organizations. Nonetheless, IHOs B and F could not provide any numbers. However, humanitarian literature suggests that these numbers could be as high as $80 \%$ to $90 \%$ (Kovács and Tatham 2009; Van Wassenhove 2006).

\section{Alleviation of transport and logistics-related challenges using UGVs and UAVs}

The last block of questions was designed to obtain the answers for the second and third research questions. The respondents were explicitly inquired about the possible role of UGVs and UAVs in the humanitarian settings and possible challenges they might face implementing these technologies in relief operations. Furthermore, they were also asked about their opinion on the maturity timeline for UGVs and UAVs and if their organizations will be willing to integrate UGVs and UAVs in their relief operations. The summary of the answers can be visualized in Table 6 (responses for UGVs) and Table 7 (responses for UAVs). Moreover, based on experts' feedback and discussion on possibilities of integrating UGVs and UAVs in the relief operation, a conceptual model was designed, which shows the integration perspective of UGVs and UAVs in a relief chain.

The discussion highlighted several potential applications, advantages, and challenges of UGVs and UAVs in humanitarian relief chain. However, IHOs A, B, D, and F were more excited for the future of relief operation with UAVs compared to UGVs, and IHOs $\mathrm{C}$ and $\mathrm{E}$ were mostly neutral in their remarks on these technologies. According to the interviewees, UGVs could be used for bulk deliveries of goods and people back and forth from the point of origin to the point of distribution, and it will be easy to set 


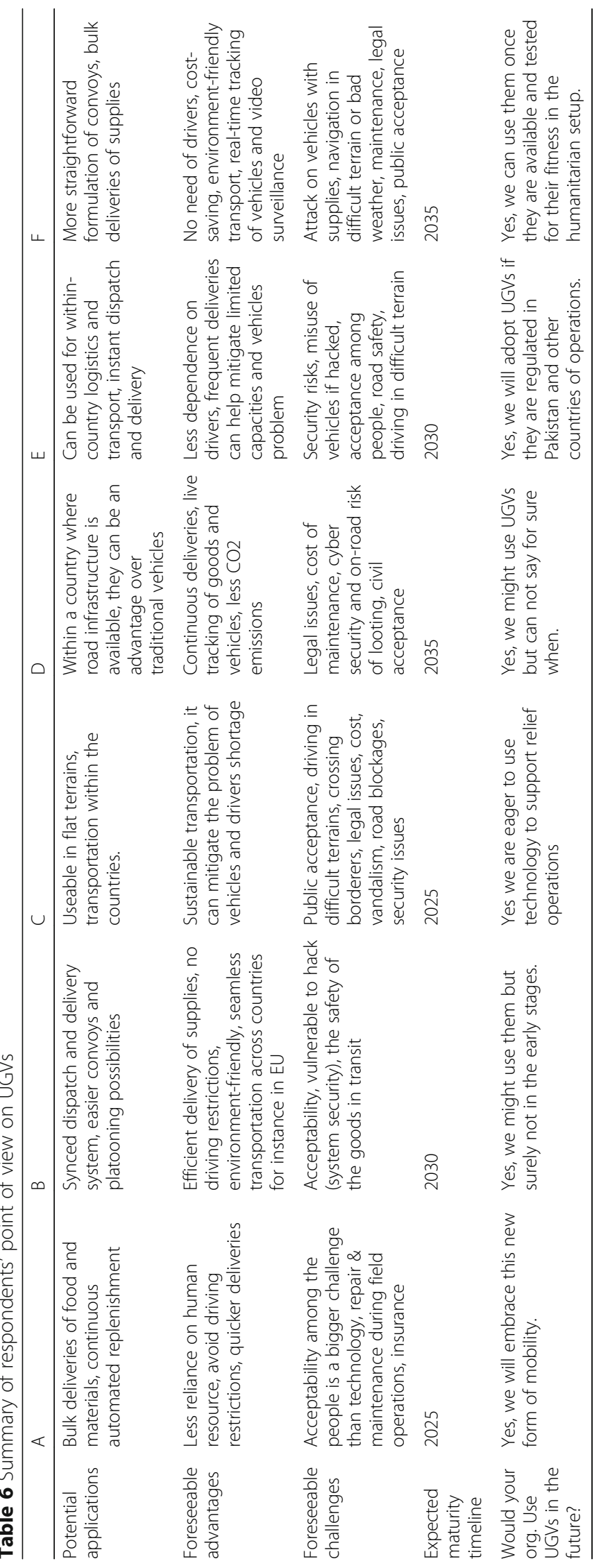




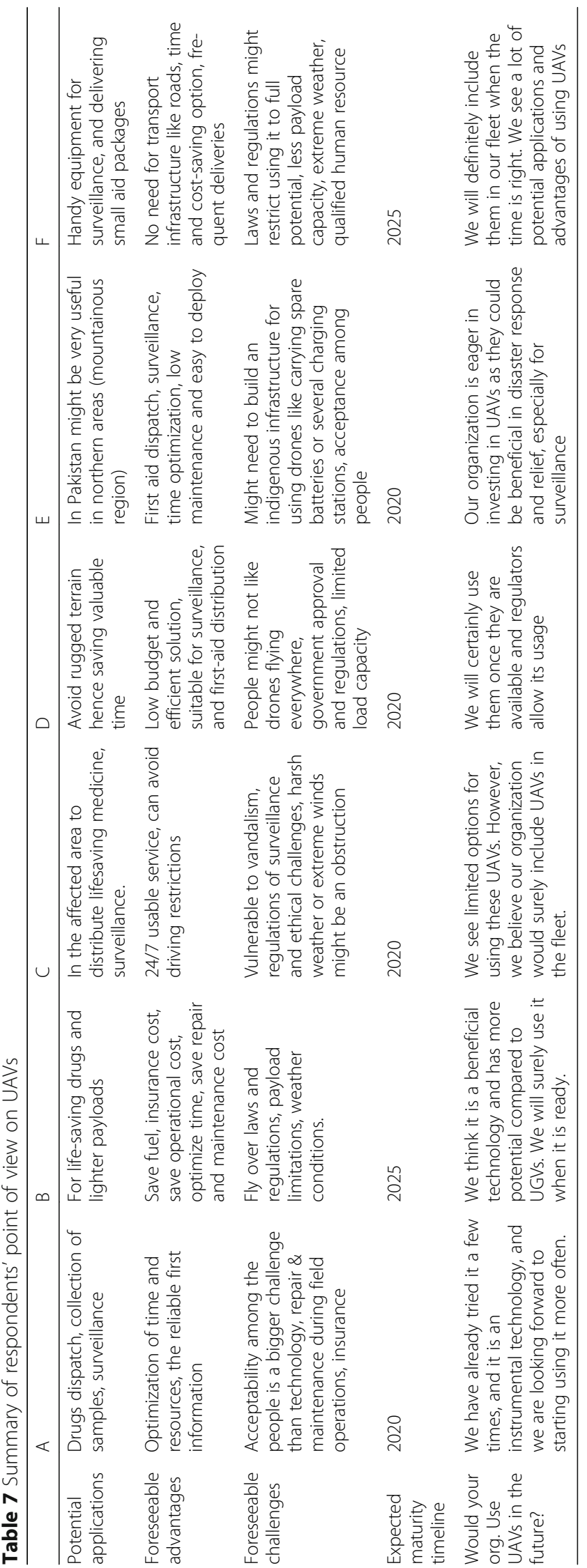


up an automatic replenishment system and help to mitigate the frequent problem of drivers shortage. Moreover, UGVs can avoid driving restrictions imposed by several countries for truck and lorry drivers resulting in quicker deliveries. Whereas, drones can be used to deliver the lifesaving drugs and less heavy payloads in the very initial phase of a disaster, which is the most critical period.

Furthermore, One IHO shared their experience of using a drone in Papua New Guinea (discussed in the literature above). The interviewee explained, "distance covered by the drones was 20-25 KM and time taken by the drone flights was on average $30 \mathrm{mi-}$ nutes or less. Previously cars were used to complete this process, which was not only more expensive but very time-consuming. The drones took 30 minutes to complete this trip, whereas conventional cars required, on average, 5 to 6 hours because of the difficult terrain." It is one useful application of drones and suggests the potential advantages IHOs could reap from this technological advancement. The successful experience of using drones in PNG motivated them to use drones for their upcoming projects too. Whereas, other participating IHOs had no such experience of using UGVs or UAVs, however, they all seem eager to adopt UAVs earlier than UGVs.

Additionally, all IHOs emphasized more on using drones in the relief operation for surveillance and sending out the lifesaving drugs or first aid. Some other notable advantages of UAVs include but are not limited to time and resources optimization, reduction in operational costs, and less reliance on humans for last-mile delivery. Furthermore, IHO A, C, D, and $\mathrm{E}$ also underlined the importance of using the autonomous vehicles, and according to them it is possible to use these vehicles in flat terrains and for the transportation within countries or across the border where road infrastructure is available, and the transportation is hindrance free.

Discussing the challenges associated with UGVs, experts mentioned that they are concerned about acceptability issues of such technologies among vulnerable people. Moreover, repair and maintenance costs, insurance, legislation, cybersecurity, and vandalism are also a few significant challenges. Similarly, UAVs also present similar challenges in addition to limited payload capacity, limited flight or operation time because of limited fuel or battery charging capacity, fly over permissions as well flight altitude issues - As drones are not allowed to fly too high because they might interfere with commercial flight path and may cause damage leading to causalities. However, they all seem to be excited and willing to adopt UGVs and UAVs if the issues mentioned above are addressed.

\section{Conceptual model for the integration of UGVs and UAVs in a relief chain}

In another question on the integration possibilities of UAVs and UGVs in the relief chain, all respondents were requested to share their opinion on how is it possible, where these UGVs and UAVs can be integrated into a humanitarian relief chain. The results of the discussion, suggestions, and expert's opinions are translated into Fig. 3.

Leg 1: The transportation of goods and volunteers from International borders to the distribution and sorting facility is considered Leg 1 . Primarily, it is the region where donors contribute goods or offer services to volunteer in a relief process. If the aid is coming from across the border, it would be considered an international donation. Otherwise, leg one and leg 2 are similar. 


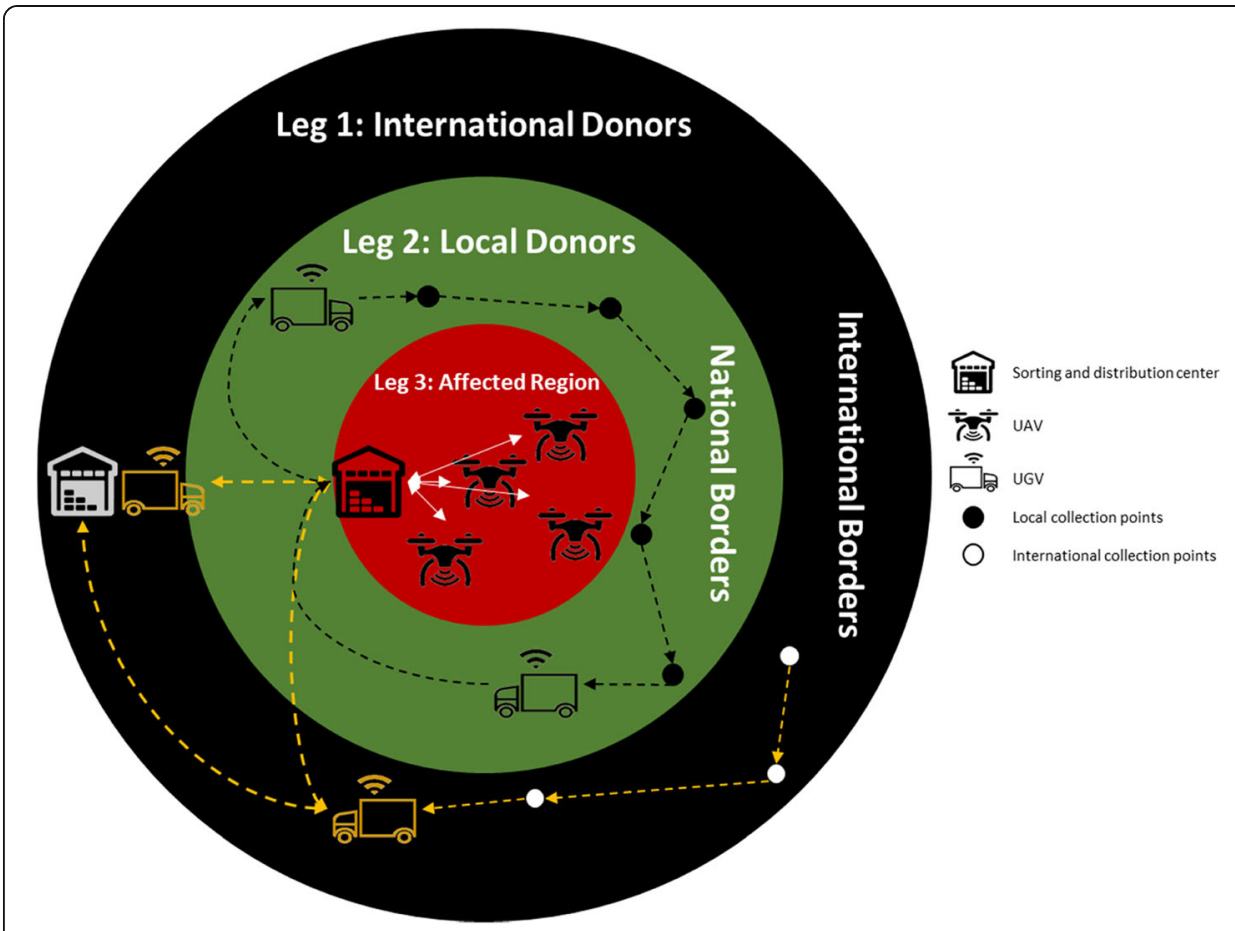

Fig. 3 Conceptual model for integration of UGVs and UAVs in a relief chain

Mobility option: for the 1st leg, UGVs could be used to collect goods and people to transport them to the sorting and distribution center either in the affected region or to international sorting and distribution facility. The transportation activity would take place within the international region or from international to affected region crossing the national region. The prerequisite for successful implementation of this system is the availability of road infrastructure, hazel free border crossing, and custom controls. The implementation of such a system is ideal in locations where a free trade agreement exists among neighboring countries. For instance, the foreseeable implementation of this concept is viable in the European Union, consider relief coming from Germany to Austria.

Leg 2: The movement of resources within Local region or national borders (affected country). It is the region where donors from several other non-affected cities send the food, medical supplies, shelter, and clothing for the beneficiaries in the affected region and also offer their services to volunteer in significant numbers.

Mobility option: Similar to the first leg, UGVs are suggested to mobilize resources within this region. The transportation activity would be carried out within national boundaries, where UGVs collect the supplies from different designated nodes and bring them to the sorting and distribution center in the affected area. Moreover, prerequisites for this leg are also no different from the leg one, minus the customs and border crossings. However, the transportation activity should be possible until at least basecamp or beyond if the infrastructure is available.

Leg 3: This leg includes but is not limited to the distribution of supplies like medicine, hygiene products, water, food to beneficiaries, and surveillance to find the best possible routes for vehicles and volunteers within the affected region (lastmile delivery). 
Mobility option: The transportation of goods within the affected region could be carried out by using UAVs. The drones would be very handy in such a situation, especially for the surveillance and delivery of small payloads to the beneficiaries in need and will save valuable time and resources, including financial resources that could be used elsewhere in a relief chain to make it more efficient and effective.

\section{Timeline for adaptation of UGVs and UAVs in the relief operation}

Interviewees form IHO A and C shared a similar stance on the time frame and adaptation of UGVs and UAVs. They stressed that seeing the rapid pace of technological advancement in the mobility sector, it is safe to believe that the future of UGVs and UAVs is not far. Both of the organizations expected this technology to be reliable enough to use in the next 10 to 15 years. However, IHO A suggested that UAV technology might mature before time and would be readily available to use in full capacity a little earlier than expected. These two IHOs were eager and excited to integrate the autonomous mobility modes in relief operation as soon as they are available.

Whereas, IHO B, D - F had slightly different opinions. The experts from these organizations suggested that they would be more willing to use drones in their relief chain once available. However, all three IHOs had a similar stance on UGVs as they were pretty resistant in claiming if they would use the autonomous vehicles in its early phase, one of the experts said: "Our organization do not want to be an early bird in using this innovative form of mobility or at least until the technology is mature and reliable enough to be adopted, we would let others experiment first." However, if we take into account the data provided by these organizations, it can be assessed that drones would become the part of the relief chain somewhere between 2020 and 2025, whereas UGVs might be between 2025 and 2035. An overview of the responses on the maturity timeline of these technologies could be visualized in Fig. 4.

\section{Conclusion}

This study had a bi-fold objective, first to identify the key logistical and transportation challenges faced by international humanitarian organizations and second to asses if these challenges could be mitigated using advanced mobility solutions like UGVs and UAVs. Therefore, we explored the possibility of integrating the most advanced form of mobility options (UGVs and UAVs) in the relief operation and assessed if these

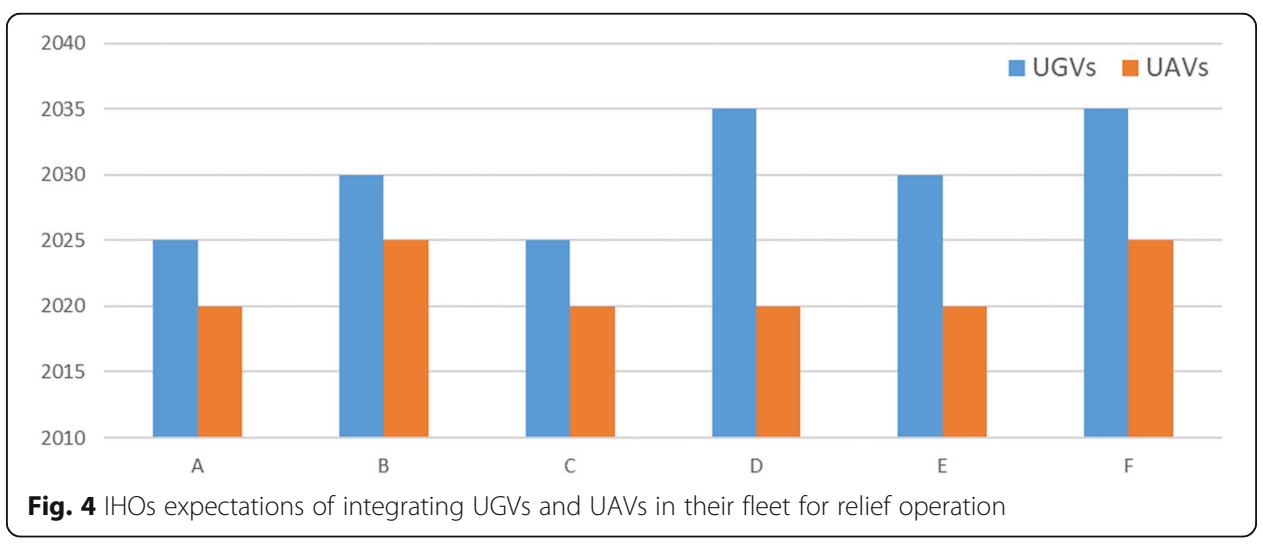


technological advancements can enhance the effectiveness and efficiency of the relief operation.

Based on the assessment of humanitarian literature and interviews, we conclude that the IHOs agree with the humanitarian literature on the transport and logistics-related challenges discussed in this study and concur that these challenges cause hindrance in the relief operation. Additionally, they suggest that using UGVs and UAVs in combination might resolve several, if not all, CSF for effective and efficient relief operation. However, IHOs suggest that UGVs are not technologically mature enough to be adopted for the relief operation; whereas, the UAVs application in the relief operation are already successfully tested and thus suggesting that UAV technology might mature earlier than UGVs. Nonetheless, when available, the IHOs are willing to test these technologies in a relief operation. In terms of its applications, IHOs bear positive hope that UGVs and UAVs will help to curb the transport and logistical challenges currently being faced by humanitarian organizations.

Lastly, it is also interesting to note that although participating organizations were from totally different geographical constituencies, still their opinions, challenges, and speculations were not entirely different. This implies that IHOs today, despite their country affiliations, face similar issues and challenges globally.

\section{Research limitations \& future research prospects}

This research is groundbreaking in its own sense; however, we acknowledge certain limitations to this study, which could create opportunities for future research. Considering the small sample size, the generalization of the results might not be appropriate in certain contexts. It is also worth noting that the model developed in this research is conceptual, and some academics might find it fuzzy. The idea of presenting the conceptual model in this study was merely to indicate the potential of integrating UGVs and UAVs in humanitarian settings and how these innovative mobility solutions might help in mitigating transport and logistics-related challenges. However, detailed operations research or field research with an ample amount of data could prove if this model is quantifiable or not.

Nonetheless, there is a need to find a feasible framework for the implementation of potential applications of UGVs and UAVs in the relief operation. Moreover, there are a very limited number of papers that discuss using UGVs in humanitarian settings. Therefore, researchers are encouraged to specifically explore this area further and find more appropriate usages of UGVs in humanitarian settings, besides exploring innovative solutions to address the conventional transport and logistics problems in humanitarian settings.

Acknowledgments

We would like to pay highest gratitude to all ten respondents for their valuable feedback and time.

Authors' contributions

The order of authorship is based on the contributions of authors i.e. M.A. $80 \%$, S.K. $20 \%$. Both authors read and approved the final manuscript.

Funding

The authors are grateful to "Kühne Stiftung" (Kühne Foundation), Switzerland for providing funds for this study.

Availability of data and materials

The data for this research was collected with an assurance of complete anonymity. Therefore, authors excuse from sharing the actual data. 


\section{Competing interests}

The authors declare that they have no competing interests.

Received: 27 September 2019 Accepted: 9 January 2020

Published online: 24 February 2020

\section{References}

Azmat M, Atif M, Kummer S (2019a) Identification and prioritization of critical success factors in faith-based and non-faithbased organizations' humanitarian supply chain. J Int Humanitarian Action 4:20

Azmat M, Kummer S (2019) Importance of key success factors for local and international NGOS in humanitarian supply chain. LogForum 15:11

Azmat M, Kummer S, Moura LT, Gennaro FD, Moser R (2019b) Future outlook of highway operations with implementation of innovative technologies like AV, CV, IoT and Big Data. Logistics 3:15

Azmat M, Kummer S, Trigueiro Moura L, Di Gennaro F, Moser R (2018) Impact of innovative technologies on highway operators: Tolling organizations' perspective. 7th Transport Research Arena (TRA 2018), Vienna, pp 1-10 http://epub.wu. ac.at/id/eprint/6273

Balcik B, Beamon BM (2008) Facility location in humanitarian relief. Int J Log Res Appl 11:101-121

Balcik B, Beamon BM, Krejci CC, Muramatsu KM, Ramirez M (2010) Coordination in humanitarian relief chains: practices, challenges and opportunities. Int J Prod Econ 126:22-34

Bealt J, Fernández B, Jair C, Mansouri SA (2016) Collaborative relationships between logistics service providers and humanitarian organizations during disaster relief operations. J Humanitarian Logistics Supply Chain Manag 6:118-144

Bierstedt J, Gooze A, Gray C, Peterman J, Raykin L, Walters J (2014) Effects of next geberation vehicles on travel demand and highway capacity. Walnut Creek, Fehr Peers Consulting

Bravo R, Leiras A (2015) Literature review of the application of UAVs in humanitarian relief. Proceedings of the XXXV Encontro Nacional de Engenharia de Producao, Fortaleza, pp 13-16

Burkart C, Besiou M, Wakolbinger T (2016) The funding-humanitarian supply chain interface. Surv Oper Res Manag Sci 21: $31-45$

Câmara D (2014) Cavalry to the rescue: Drones fleet to help rescuers operations over disasters scenarios, 2014 IEEE conference on Antenna Measurements \& Applications (CAMA). IEEE, pp 1-4

Celik E, Gumus AT, Alegoz M (2014) A trapezoidal type-2 fuzzy MCDM method to identify and evaluate critical success factors for humanitarian relief logistics management. J Intell Fuzzy Syst 27:2847-2855

CIA. 2017. The World Factbook. USA: Central Inteligence Agency Available: https://www.cia.gov/library/publications/theworld-factbook/geos/pp.html. Accessed 01.082018

Costa SRAD, Campos VBG, Bandeira RADM (2012) Supply chains in humanitarian operations: cases and analysis. Procedia Soc Behav Sci 54:598-607

CWO. 2017. papua-new-guinea. The Common Wealth Organization. Available: http://thecommonwealth.org/our-membercountries/papua-new-guinea. Accessed 01.082019

Dale JM, Dulaimi MF (2016) Cultural competence - a success factor in NGO projects? Built Environ Proj Asset Manag 6:232246

Dasaklis TK, Pappis CP (2018) Critical success factors for implementing cholera vaccination campaigns in humanitarian emergencies: a DEMATEL-based approach. EURO J Decis Processes 6:1-20

Day JM, Melnyk SA, Larson PD, Davis EW, Whybark DC (2012) Humanitarian and disaster relief supply chains: a matter of life and death. J Supply Chain Manag 48:21-36

De Sousa JB, Gonçalves GA, Pereira FL (2008) Autonomous vehicles in the response to maritime incidents. IFAC Proc Vol 41 : $67-72$

Desaulniers M, Bajic M, Cepolina E, Zoppi M (2013) TIRAMISU: FP7-project for an integrated toolbox in humanitarian demining, focus on UGV, UAV and technical survey

Dobrovnik M, Herold D, Fürst E, Kummer SJL (2018) Blockchain for and in Logistics: What to Adopt and Where to Start. Logistics 2:18

Dube N, Vaart TVD, Teunter RH, Wassenhove LNV (2016) Host government impact on the logistics performance of international humanitarian organisations. J Oper Manag 47:44-57

Eriksson M, Karlsson E (2017) Critical success factors' impact on agility of humanitarian supply chains. Masters Master Thesis Jonkoping university

Ferris E (2005) Faith-based and secular humanitarian organizations. Int Rev Red Cross 87(858):311-325 Red Cross

FSD (2016) Drones in humanitarian action. Switzerland Swiss Foundation for Mine Action (FSD)

Gkartzonikas C, Gkritza K (2019) What have we learned? A review of stated preference and choicestudies on autonomous vehicles. Transp Res C 98:323-337

Hall AR, Coyne CJ (2013) The political economy of drones. Defence Peace Econ 25:445-460

Ivancevic V, Yue Y (2016) Hamiltonian dynamics and control of a joint autonomous land-air operation. Nonlinear Dynamics 84:1853-1865

Jahre M, Persson G, Kovács G, Spens KM (2007) Humanitarian logistics in disaster relief operations. Int J Phys Distrib Logistics Manag 37(2):99-114. https://doi.org/10.1108/09600030710734820.

Kabra G, Ramesh A (2015a) Analyzing drivers and barriers of coordination in humanitarian supply chain management under fuzzy environment. Benchmarking 22:559-587

Kabra G, Ramesh A (2015b) Segmenting critical factors for enhancing the use of IT in humanitarian supply chain management. Procedia Soc Behav Sci 189:144-152

Kovács G, Tatham P (2009) Humanitarian logistics performance in the light of gender. Int J Product Perform Manag 58:174187

Kyriakidis M, Happee R, Winter JCFD (2015) Public opinion on automated driving: results of an international questionnaire among 5000 respondents. Transport Res F: Traffic Psychol Behav 32:127-140 
Litman T (2015) Autonomous vehicle implementation predictions: implications for transport planning. Victoria Transport Policy Institute, Victoria

Maghsoudi A, Zailani S, Ramayah T, Pazirandeh A (2018) Coordination of efforts in disaster relief supply chains: the moderating role of resource scarcity and redundancy. Int J Logistics Res Appl 21:407-430

Mahmassani HS (2016) Autonomous vehicles and connected vehicle systems: flow and operations considerations. Transp Sci 50:1140-1162

Mahmood Z, Kouser R, Masud MAK (2019) An emerging economy perspective on corporate sustainability reporting - main actors' views on the current state of affairs in Pakistan. Asian J Sustainability Soc Responsibility 4:8

Martinez AJP, Orla S, Wassenhove LNV (2011) Field vehicle fleet management in humanitarian operations : a case-based approach. J Oper Manag 29:404-421

Milakis D, Snelder M, Arem BV, Wee BV, Correia GHDA (2017) Development and transport implications of automated vehicles in the Netherlands: scenarios for 2030 and 2050. Eur J Transp Infrastructure Res:63-85

Moshtari M, Gonçalves P (2016) Factors influencing Interorganizational collaboration within a disaster relief context. Volunt Int J Volunt Nonprofit Org 28:1673-1694

Mosterman PJ, Escobar Sanabria D, Bilgin E, Zhang K, Zander J (2014) Automating humanitarian missions with a heterogeneous fleet of vehicles. Annu Rev Control 38:259-270

MSF. 2014. Papua New Guinea: Innovating to reach remote TB patients and improve access to treatment. Available: http:// www.msf.org/en/article/papua-new-guinea-innovating-reach-remote-tb-patients-and-improve-access-treatment. Accessed 03.082019

Ngwenya NK, Naude MJA (2016) Supply chain management best practices: a case of humanitarian aid in southern Africa. J Transp Supply Chain Manag 10:242

Oloruntoba R (2010) An analysis of the cyclone Larry emergency relief chain: some key success factors. Int J Prod Econ 126: 85-101

Patton MQ (2002) Qualitative Research \& Evaluation Methods. CA, Sage Publications, Thousand Oaks

Pettit S, Beresford A (2009) Critical success factors in the context of humanitarian aid supply chains. Int J Phys Distrib Logistics Manag 39:450-468

Richey RG, Kovács G, Spens K (2009) Identifying challenges in humanitarian logistics. Int J Phys Distrib Logistics Manag

Scarpin MRS, Silva RDO (2014) Humanitarian logistics: empirical evidences from a natural disaster. Procedia Eng 78:102-111

Scholten K, Scott PS, Fynes B (2006) (Le) agility in humanitarian aid (NGO) supply chains. Int J Phys Distrib Logistics Manag: $115-120$

Seitz P (2015) Disaster-response robots slow in coming, USA. https://www.investors.com/news/technology/click/darparobotics-challenge-starts-with-emergency-response-robots/

Seuring S, Gold S (2012) Conducting content-analysis based literature reviews in supply chain management. Supply Chain Manag 17:544-555

Stajura M, Glik D, Eisenman D, Prelip M, Martel A, Sammartinova J (2012) Perspectives of community- and faith-based organizations about partnering with local health departments for disasters. Int J Environ Res Public Health 9:2293-2311

Tanzi TJ, Chandra M, Isnard J, Camara D, Sebastien O, Harivelo F (2016) Towards "drone-borne" disaster management: future application scenarios, XXIII ISPRS Congress, Commission VIII, vol III-8. Copernicus GmbH, pp 181-189

Tatham P, Ball C, Wu Y, Diplas P (2017a) Long-endurance remotely piloted aircraft systems (LE-RPAS) support for humanitarian logistic operations: The current position and the proposed way ahead. J Humanitarian Logistics Supply Chain Manag 7:2-25

Tatham P, Houghton L (2011) The wicked problem of humanitarian logistics and disaster relief aid. J Humanitarian Logistics Supply Chain Manag 1:15-31

Tatham P, Stadler F, Murray A, Shaban RZ (2017b) Flying maggots: a smart logistic solution to an enduring medical challenge. J Humanitarian Logistics Supply Chain Manag 7:172-193

Thurmond VA (2001) The point of triangulation. J Nurs Scholarsh 33:253-258

Van Wassenhove LN (2006) Humanitarian aid logistics: supply chain management in high gear. J Oper Res Soc 57:475-489

Van Wassenhove LN (2017) Humanitarian aid logistics: supply chain management in high gear. J Oper Res Soc 57:475-489

Wintersberger S, Azmat M, Kummer S (2019) Are we ready to ride autonomous vehicles? A Pilot Study on Austrian Consumers' Perspective. Logistics 3:20

Wyse, S. E. 2011. What is the difference between qualitative research and quantitative research? www.snapsurveys.com. Available: https://www.snapsurveys.com/blog/what-is-the-difference-between-qualitative-research-and-quantitativeresearch/. Accessed 16 Sept 2019

Yadav DK, Barve A (2015) Analysis of critical success factors of humanitarian supply chain: an application of interpretive structural Modeling. Int J Dis Risk Reduction 12:213-225

Yadav DK, Barve A (2018) Segmenting critical success factors of humanitarian supply chains using fuzzy DEMATEL. Benchmarking 25:400-425

Young LA (2006) Future roles for autonomous vertical lift in disaster relief and emergency response. Aichi, Japan: Flight Vehicle Research and Technology Division, Ames Research Center, NASA, Heli Japan

\section{Publisher's Note}

Springer Nature remains neutral with regard to jurisdictional claims in published maps and institutional affiliations. 